\title{
Talking to Children About
}

Sean Brotherson, Ph.D.

Family Science Specialist,

NDSU Extension Service

Children, especially young children, may experience challenging

emotions when faced with stress

resulting from exposure to terrorist

acts. From the bombing of the

Federal Building in Oklahoma City

to the tragedy of Sept. 11 to

terrorist events that occur in other

parts of the world (e.g., Israel,

Spain, London, Pakistan),

exposure to terrorism and

its graphic results is a common

experience for many children today.

Parents and other adults can best

support children through kindness, understanding and reassurance.

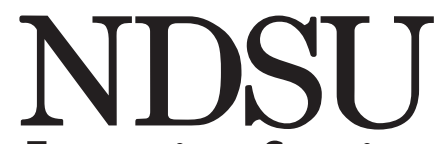

Extension Service

North Dakota State University

Fargo, North Dakota 58105

MAY 2006

\section{What is Terrorism?}

The face of violence is complex.

Children see the reactions of parents and other adults to terrorism and feel the anxiety and confusion that result from such events.

Terrorism essentially consists of the systematic or planned use of violence or the threat of violence toward civilians, groups or societies with the intent to kill, injure, harm, coerce or intimidate through fear and terror, often in pursuit of political or ideological goals. Although terrorism has a long history, terrorism in the world today appears to have increased in recent decades in its frequency, sophistication and impact. Media coverage of terrorist events has increased significantly and public responses from government and other entities have expanded, so children are more likely not only to be exposed to terrorism but to experience ongoing awareness of its effects.

Children see adults absorbed in the news coverage. They listen to parents or teachers discussing personalities associated with terrorism or items in the news. Children often want to know what is happening, express concern and anxiety, and wonder why it is happening at all.

\section{Responses of Children to Terrorism}

Acts of human violence tend to create uncertainty, fear and insecurity in children. Terrorist acts often are similar in their impact on children to other disasters, which tend to be events that are quite sudden, very disruptive, lasting in their effects and public in their impact.

Children who express emotional strain due to terrorist incidents may be responding to at least four sources of stress:

- They are dealing with the sudden and unexpected upheaval that events and the resulting societal challenges cause.

- They may have to cope with weeks or months of continuing disturbance in life routines or mental patterns because of media coverage, public security, etc.

- They may be responding to increased patterns of stress and difficulty parents or other adults feel, and which change the family's patterns and emotional atmosphere.

- They may be worrying about the possible impact on themselves or others they know, internalizing the events in a manner that reflects fear or anxiety. 


\section{How Adults Can Help Children Deal with Stress from Terrorism}

Parents and other adults are critical in helping children deal with the stress of terrorist events in at least four ways. They provide an example for children, create a supportive environment, act as a resource, and give guidance and support in managing feelings.

- First, as adults, set an example for children that helps them understand how to handle concerns about terrorist events or any other challenge. Children look to parents or other adults for insight into how to respond to difficult circumstances or events. Set a supportive example for children. Avoid responding to current news updates in ways that are highly emotional or overly dramatic. Such reactions may upset children. Be informed but don't dwell at length on the latest events.

Second, create a supportive environment for children during highly stressful events. Maintain a sense of security in your own home and environment. It reassures children they can continue to feel secure. Continue a healthy routine at home. Avoid letting the news coverage of current terrorist events be on television or radio constantly in the background. This creates tension and may overwhelm a child's sense of security.

Third, parents and other adults should be a resource for helping children cope as needed. Express your concern for people living in areas where terrorist events take place, but also reassure children about their protection and safety. Answer your children's questions directly but give them information that is appropriate to their age and maturity level. Listen to them if they want to express concerns.

Fourth, help children manage fears or uncertainty they might feel or express. Parents and other adults need to be attentive to children's needs in helping them overcome fears or maintain a sense of trust and security.

\section{Awareness of Children at Risk Following Terrorism}

In the aftermath of terrorist incidents, parents and other adults should be aware that some children are most likely to be at risk for problems needing attention. Children are most likely to suffer negative effects due to:

- Physical proximity - witnessing the event directly or being near the location of the incident

- Emotional exposure - having a family member or friend affected by the incident, especially if the person is hurt, missing or dead

- Pre-existing mental health issues - emotional or mental disturbances or anxieties already present in the child

- Pre-existing loss or trauma experience - previous experience with significant loss or trauma as a child

\section{Talking to Young Children (ages 4 to 8)}

When talking to young children from ages 4 to 8 :

\section{Common Reactions of Young Children}

- Separation concerns or fears, clinging or searching for parents

- Tantrums or irritability

- Anger or aggression (yelling, threatening, hitting, etc.)

- Withdrawal or restlessness (isolation, change in normal routines)

- Regressive behaviors (thumb sucking, clinging to adults, wetting bed, etc.)

- Sleep or physical problems (disturbance of sleep, nightmares, stomach problems or other symptoms of physical distress)

\section{What to Say and Do}

- Ask children to share their thoughts and feelings with you. Let them know this is a topic they can ask questions about. Ask if they feel scared or angry, and let them know such feelings are normal and can be worked out.

- Allow repetitive questions and a search for understanding. Give honest and clear answers, such as "some people do harmful things" or "bad actions hurt people."

- Monitor adult conversations around children. Avoid talking about enemies or violence, as this can upset young children.

- Give children physical comfort and verbal reassurance of safety. Young children need to hear and feel messages of support and security.

- Help children express feelings through play, drawing or telling a story. Ask them about a story or picture related to events and what it means to them. 


\section{Talking to Middle Children (ages 9 to 13)}

When talking to middle children from ages 9 to 13:

\section{Common Reactions of Middle Children}

- Fears and anxiety, concern about being alone or what else might happen

- Anger or aggression toward siblings or peers, or toward parents preoccupied by dealing with stress

- Sadness about events and loss, isolation, tendency to withdraw

- Sleep or physical problems (disturbance of sleep or other symptoms of physical distress)

- Repetitive thoughts, questions about event, discussion and concern

- Exaggerated attempts to protect or help parents, other adults

\section{What to Say and Do}

- Encourage expression of feelings and listen carefully to children. Ask questions so a child can direct the conversation and you can assess the child's thoughts and feelings.

- Reassure children about their safety. Explain what you as a parent and others will do to provide security. However, do not ignore the terror associated with events. Acknowledge children's concerns for others.

- Monitor exposure to media coverage of terrorist events. Reduce exposure to television or radio coverage.

- Ask children what they know about an event and how they know it. They may have discussed events at school with peers or teachers. Find out if they have additional questions and correct misinformation they may have.

- Read books or watch movies together that involve dealing with challenges. Ask children what they think about characters and how they respond.
- Allow children to participate in opportunities such as attending a memorial service, making a donation, providing service or other appropriate activities.

- Show children an example of self-control and positive coping when such events occur. An example of maturity and caring will help children as they respond.

\section{Talking to Adolescents (ages 14 to 18)}

When talking to teens from ages 14 to 18 :

\section{Common Reactions of Adolescents}

- Numbness, shock, reliving of events

- Discouragement, disillusionment and pessimism about life, people

- Mood swings, irritability, anxiety, emotional distance and isolation

- Acting out, engaging in risky behaviors, substance use

- Fear of similar events, death, betrayal of the future, etc.

- Thoughts about the future, concern about well-being of themselves and others

\section{What to Say and Do}

- Encourage expression of feelings and listen. Allow for continuing discussion of events, give time to talk, and provide reassurance.

- Discuss events with your teens. Assess how they feel about events and people associated with violent acts. Encourage thinking about "harmful acts" rather than "evil people" or groups, with the intent to avoid stereotypes and recognize that people have power to choose their acts toward others.

- Establish and maintain consistent routines that involve teens, such as regular meals, bedtime routines or playing family games.

- Develop a plan with teens for action if events that might affect the family or community occur. This may include knowledge of contact information, awareness of first aid or simply greater understanding of potential concerns.

- Involve teens in service activities. Contributing or assisting with responding to events, such as performing a service activity for people in need, can help them

- Engage teens in activities that relieve stress. Suggestions might include walking or other types of exercise, listening to music or engaging in spiritual activities.

- Slow down and help teens appreciate the positive things in life. Terrorism aims to rob individuals and families of security and normalcy. Find hope in the kindness shared by a neighbor. Share happiness in moments of family warmth, humor, and caring words and gestures.

\section{Recommended Resources}

PBS Parents Web Site - "Talking with Kids About War and Violence" - Web site: www.pbs. org/parents/talkingwithkids/war/

American Psychological Association Help Center Featured Topics, "Resilience in a Time of War" - Web site: www.apahelpcenter.org/ featuredtopics/

- Purdue Extension - "Terrorism and Children" - Web site: www.ces.purdue.edu/terrorism/

- National Association of School Psychologists, Crisis Resources War/Terrorism Materials Web site: www.nasponline.org/ NEAT/crisismain.html\#war

- NYU Child Study Center Public Mental Health - Web site: wwww.aboutourkids.org/aboutour/ articles_public.html

NDSU Extension Service "Talking to Children About Terrorism" Web Site - Web site: www.ag.ndsu.nodak.edu/ terrorism.htm 


\section{Children and Images of Violence}

Terrorist acts are intended specifically to spread fear and anxiety in the general population. This means acts of violence are calculated to shock and terrify, and individuals or groups may provide images and messages that further spread fear and concern. Extensive media coverage of images of violence worsens this problem and is a cause of concern for parents and other adults. Children witnessing or being exposed to images of terrorism and violence can suffer trauma and negative effects.

Some things to consider:

- Help children establish a set of values to guide their responses and actions. Guide children to develop values that look to the future, connect them to larger groups and encourage positive behavior. Discuss how to think about violent acts and ways to be empathic for people such acts affect.

\section{- Speak to a child's level of} understanding. Concepts raised by terrorism include distinctions between right and wrong, cultural values and moral behavior. Adapt your conversation to a child's level of understanding.

- Avoid constant and harsh exposure to images of violence through television or other media. Be aware of how much children see on TV or the Internet, and set limits. Repeated exposure to images of violence can lead to trauma, anxiety or unhealthy responses.
- Be available to discuss what your children see and help them make sense of disturbing images. Discussion with children may help clarify the context of what they are seeing and help them understand what happened, rather than just seeing disturbing visual images.

- Reduce exposure to images of violence in children's lives. Feelings of fear and threats that occur due to exposure to violence can affect children negatively, even at the level of brain functioning and development. Limit exposure to violent images whether on television, in video games or movies, or other contexts.

\section{- Teach children alternatives} to violence are available and discuss peaceful methods of action. Emphasize that acts of violence committed for the purpose of terrorism are wrong, and that alternative methods of dealing with problems exist. Learn about and discuss alternative options when conflict occurs.

\section{References}

Brotherson, S.E. (2001). Extension and other resources for responding to terrorism of September 11, 2001 - Educator's resource packet. Fargo, N.D.: NDSU Extension Service.

Gallagher, R., and A. Chase. (2002). Building resilience in children in the face of fear and tragedy. New York: New York University Child Study Center. Online at: www.aboutourkids.org/aboutour/articles/ crisis_resilience.html

Goodman, R.F. (2006). Talking to kids about terrorism or acts of war. New York: New York University Child Study Center. Online at: www.aboutourkids.org/aboutour/ articles/war.html

Goodman, R.F., E.J. Brown, M. Courtney and A. Gurian. (2002). The aftermath of disaster: Helping children affected by trauma and death. NYU Child Study Center Letter, 7(1). New York: New York University Child Study Center.

Goodman, R.F., et al. (2002). Caring for kids after trauma and death: A guide for parents and professionals. New York: New York University Child Study Center. Online at: www.aboutourkids.org/articles/ crisis_index.html

Greenman, J. (2001). What happened to the world? Helping children cope in turbulent times. Washington, D.C.: National Association for the Education of Young Children.

La Greca, A.M., W.K. Silverman, E.M. Vernberg and M.C. Roberts (Eds.). (2002). Helping children cope with disasters and terrorism. Washington, D.C.: American Psychological Association.

Myers-Walls, J. (2002). Talking to children about terrorism and armed conflict. The Forum for Family and Consumer Issues, 7(1). Online at: www.ces.ncsu.edu/depts./ fcs/pub/2002w/myers-wall.html

\section{For more information on this and other topics, see: www.ag.ndsu.edu}

This publication may be copied for noncommercial, educational purposes in its entirety with no changes.

Requests to use any portion of the document (including text, graphics or photos) should be sent to NDSU.permission@ ndsu.edu. Include exactly what is requested for use and how it will be used. 